\section{Cureus}

Received 09/10/2018

Review began 09/18/2018

Review ended 09/18/2018

Published 09/26/2018

\section{(c) Copyright 2018}

Gnanadev et al. This is an open access article distributed under the terms of the Creative Commons Attribution License CC-BY 3.0., which permits unrestricted use, distribution, and reproduction in any medium, provided the original author and source are credited.

\title{
An Unusual Finding of the Hyoid Bone
}

Raja Gnanadev ${ }^{1}$, Joe Iwanaga ${ }^{2}$, Marios Loukas ${ }^{3}$, R. Shane Tubbs ${ }^{4}$

1. Miscellaneous, Seattle Science Foundation, Seattle, USA 2. Medical Education and Simulation, Seattle Science Foundation, Seattle, USA 3. Medical Education and Simulation, St. George's University School of Medicine, St. George, GRD 4. Neurosurgery, Seattle Science Foundation, Seattle, USA

$\square$ Corresponding author: Joe Iwanaga, joei@seattlesciencefoundation.org

Disclosures can be found in Additional Information at the end of the article

\section{Abstract}

The hyoid contributes to many biomechanical processes including swallowing. Additionally, the hyoid bone has been studied for over a century in an effort to catalog and categorize many observed biometric differences. This has led to the hyoid being a major structure involved in forensic pathology. In this paper, we discuss a very unusual finding of an adult female hyoid bone.

Categories: Pathology

Keywords: hyoid, larynx, ossification, omohyoid, variation, myositis ossificans, forensic pathology

\section{Introduction}

The hyoid bone is a unique structure in the human body for many reasons. The larynx is an extremely cartilaginous area, except for the sole regional bony structure-the hyoid bone. Famously, the hyoid bone is the only bone in humans that does not articulate with any other bone, but only has muscular, ligamentous, and cartilaginous attachments. Given this peculiarity, it has been described as "free floating" [1].

Given that the vast number of muscles is attached to the hyoid, it is no surprise that the hyoid bone contributes to actions such as mastication and swallowing. Additionally, variations in morphometric data between the sexes have been well studied and have had a strong contribution to forensic medicine for decades [2-3].

Herein, we report an unusual variation of the hyoid bone and briefly review morphometric studies on hyoid bone anatomy.

\section{Case Presentation}

During the routine dissection of the head and neck of an adult female Caucasian fresh frozen cadaver, an unusual morphology of the hyoid bone was observed. The sternohyoid and omohyoid muscles are attached to the lower border of the hyoid body as usual. The hyoid bone was resected from the anterior neck and the soft tissues on the bone were removed. The height of the body of the hyoid bone then was found to be larger than normal and measured $15.9 \mathrm{~mm}$ (Figure 1). However, the greater cornu and lesser cornu were found to be normal in size and orientation. The inferior edge of the body of the bone was drawn out and presented with an unusual edge at the site of attachment of the omohyoid and sternohyoid muscles. No previous scars or evidence of trauma was found in this specimen in the region dissection. Additionally, no other anatomical variations were noted. 


\section{Cureus}

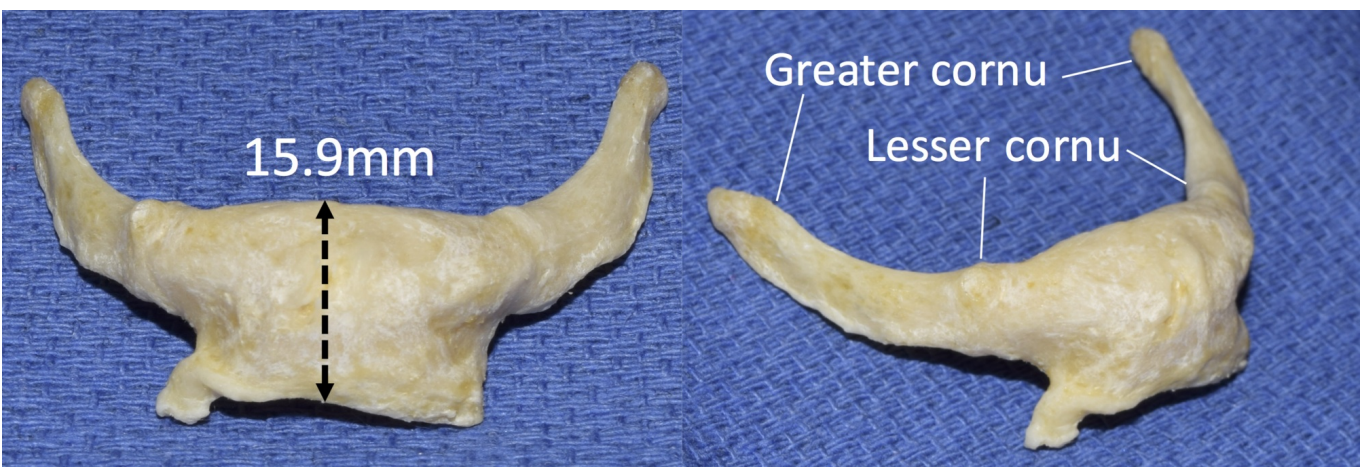

FIGURE 1: Measurement of the variant hyoid bone.

\section{Discussion}

The hyoid bone is located inferior to the mandible, and superior to the thyroid cartilage at the level of the third cervical vertebra in the midline. Laryngeal muscles attach on the superior body, inferior body, and laterally along the each of the horns. Embryologically, the cartilage of the second pharyngeal (hyoid) arch forms the lesser horn and that of the third pharyngeal arch gives rise to the greater horn. The ventral side of the second and third pharyngeal arches fuses to form the body of the hyoid bone during the fourth week of gestation.

This report focuses on the inferior part of the hyoid body where the omohyoid and sternohyoid muscles attach. An elongated body $(15.9 \mathrm{~mm})$ along this inferior edge was noted in the specimen.

Many researchers have investigated the sex dimorphism observed regarding the hyoid bone and the variation appears to be consistent across many measurements. These variations include angles of measurement from the body to the greater and lesser tubercles, length of the horns, and thickness of the body, among many others [1-3]. By cataloging these variations, forensic pathologists have been able to use hyoid bone morphology with relatively good accuracy to make determinations related to identifying the deceased [3]. Given the significance of being able to do this, a relatively complex categorization system has been developed for various known shapes of the hyoid. Remarkably, it has been noted that $60 \%$ of hyoid bones still do not fit into one of these commonly described categories [4].

Unfortunately, there are few studies that have analyzed the distance from the superior border to the inferior border of the body. A search of the literature has yielded just two studies, separated by over a century, with metrics on this dimension of the hyoid. In 1909, Parsons analyzed the hyoid bone from 108 adult cadavers from male adults (53), female adults (28), and children (27). His results showed an average height of $1.2 \mathrm{~cm}$ for males (range: $1.0-1.6 \mathrm{~cm}$ ), and $1.0 \mathrm{~cm}$ for females (range: 0.9-1.2 cm) [5]. In 2012, a group of Japanese researchers analyzed 600 hyoid bones (310 males, 290 females) using three-dimensional computed tomography (CT) imaging. Their data closely matched that of the 1909 study showing a mean height of $9.4 \mathrm{~mm}$ in males (range: 6.3-16.0 mm), and $7.8 \mathrm{~mm}$ in females (range: $3.0-8.8 \mathrm{~mm}$ ) [6]. However, the exact morphology of the hyoid bone in these cases was not reported.

Finally, there are reported cases of ossification of the muscles that attach to the hyoid bone, e.g., traumatic and genetic myositis ossificans [7]. A review of the literature yielded a single case report on traumatic myositis ossificans in the superior belly of the omohyoid. In this case, the ossification was unilateral, palpable on physical examination, and clearly visible on radiographs [8]. 
Anatomical variations such as the one described herein, can result in wrong level surgery as the normally positioned and sized hyoid bone is used by surgeons to estimate the C3 vertebral level [9-12]. Furthermore, as the anterior neck is often palpated during physical examination, bony variants such as the one described here could lead to misdiagnosis or at least, unnecessary testing.

\section{Conclusions}

The hyoid bone has both many unique anatomical features and clinical relevance in forensic pathology. Therefore, reports of hyoid bone variations are important to anatomists and clinicians alike.

\section{Additional Information Disclosures}

Human subjects: Consent was obtained by all participants in this study. Conflicts of interest: In compliance with the ICMJE uniform disclosure form, all authors declare the following: Payment/services info: All authors have declared that no financial support was received from any organization for the submitted work. Financial relationships: All authors have declared that they have no financial relationships at present or within the previous three years with any organizations that might have an interest in the submitted work. Other relationships: All authors have declared that there are no other relationships or activities that could appear to have influenced the submitted work.

\section{References}

1. Fakhry N, Puymerail L, Michel J, et al.: Analysis of hyoid bone using 3D geometric morphometrics: an anatomical study and discussion of potential clinical implications. Dysphagia. 2013, 28:435-445.

2. O'Halloran RL, Lundy JK: Age and ossification of the hyoid bone: forensic implications . J Forensic Sci. 1987, 32:1655-1659.

3. Kim D-I, Lee U-Y, Park D-K, et al.: Morphometrics of the hyoid bone for human sex determination from digital photographs. J Forensic Sci. 2006, 51:979-984.

4. Papadopoulos N, Lykaki-Anastopoulou G, Alvanidou E: The shape and size of the human hyoid bone and a proposal for an alternative classification. J Anat. 1989, 163:249-260.

5. Parsons FG: The topography and morphology of the human hyoid bone. J Anat Physiol. 1909, 43:279-290.

6. Ito K, Ando S, Akiba N, et al.: Morphological study of the human hyoid bone with threedimensional CT images - gender difference and age-related changes. Okajimas Folia Anat Jpn. 2012, 89:83-92.

7. Aoki T, Naito H, Ota Y, Shiiki K: Myositis ossificans traumatica of the masticatory muscles: review of the literature and report of a case. J Oral Maxillofac Surg. 2002, 60:1083-1088.

8. Read-Jones M, Murty GE, Ward V: Traumatic myositis ossificans of the superior belly of the omohyoid. J Laryngol Otol. 1999, 113:856-857.

9. Badshah M, Soames R, Ibrahim M, Khan MJ, Khan A: Surface anatomy of major anatomical landmarks of the neck in an adult population. Clin Anat. 2017, 30:781-787.

10. Shen X-H, Xue H-D, Chen Y, et al.: A reassessment of cervical surface anatomy via CT scan in an adult population. Clin Anat. 2017, 30:330-335. http://www.ncbi.nlm.nih.gov/pubmed/28192864.

11. Sanchis-Gimeno JA, Perez-Bermejo M, Rios L, et al.: Analysis of the relationship between the double transverse foramen and the possibility of developing clinical symptoms after whiplash. Clin Anat. 2017, 30:761-766.

12. Burulday V, Akgül MH, Bayar Muluk N, Yağdiran B, Inal M: The importance of medial-lateral styloid process angulation/coronal plane angle in symptomatic eagle syndrome. Clin Anat. 2017, 30:487-491. 